\title{
Language learning motivation in collaborative online international learning: an activity theory analysis
}

\section{Tomoe Nishio', Chie Fujikake², and Masataka Osawa}

\section{Abstract}

his study investigated the development of language learning motivation in an American student of Japanese, Jason, during a mobility-based Collaborative Online

_ International Learning (COIL) project with a Japanese institution. Drawing on an activity theory perspective, this qualitative case study analyzed the student artifacts of the project as well as of interview and fieldnote data to illustrate the transformational process. Findings demonstrate how Jason's pre-COIL motives (pragmatic, cultural, linguistic, and intellectual) were negotiated while participating in the COIL project. Through interacting with Japanese students, Jason's preexisting linguistic demotivation was reversed by his positive reevaluation of his own oral skills, which enhanced his desire for higher proficiency. The project also stimulated Jason's intellectual motive to learn Japanese using technology, leading to his autonomous choice to research language learning and technology, and to create a podcast. It is argued that Jason's motivation for Japanese learning was enhanced through the social process, during which motives were transformed along with personal significance to him.

\section{Keywords: motivation; activity theory; COIL; student voices; Japanese.}

1. University of North Georgia; Tomoe.Nishio@ung.edu; https://orcid.org/0000-0001-7760-8303

2. Nanzan University; fujikake@nanzan-u.ac.jp; https://orcid.org/0000-0002-4461-8123

3. Nanzan University; mosawa@nanzan.ac.jp; https://orcid.org/0000-0002-4072-2601

How to cite this article: Nishio, T., Fujikake, C., \& Osawa, M. (2020). Language learning motivation in collaborative online international learning: an activity theory analysis. Journal of Virtual Exchange, 3(SI-IVEC2019), 27-47. https://doi.org/10.21827/jve.3.35780 


\section{Introduction}

In the last few decades, many institutions of higher education as well as governments have put considerable emphasis on study abroad programs as part of the internationalization of their curriculum (Altbach \& Knight, 2007; Villar-Onrubia \& Rajpal, 2015). Following the trend of student mobility, various forms of virtual exchange enabled by technology have emerged, allowing those who are unable or unwilling to engage in physical mobility programs to gain international experience (Kinginger, 2009; O'Dowd, 2016). COIL is a form of virtual exchange that involves connecting two or more classes in different locations under the guidance of teachers or trained facilitators (O'Dowd, 2016), and it has become one of the largest virtual exchange networks in the world (O'Dowd, 2018). There is no one definitive COIL methodology and a COIL project could take various forms in terms of collaboration at the administrative level as well as of student interaction (O'Dowd, 2018). For example, collaboration can range from a semester-long, joint syllabus model to a short-term assignment; while some projects can be completely online, others may involve student mobility.

An increasing number of expository articles and empirical studies have reported various COIL models (Foster, 2015; O’Dowd, 2016, 2018; Rubin, 2016; Villar-Onrubia \& Rajpal, 2015). However, as COIL is a new educational modality, literature on student voices in the field is relatively sparse, as the existing research tends to focus on affordances of COIL and assessment methodology for student learning outcomes from an administrative perspective. In recent years, there has been an increasing number of studies on student voices from various COIL projects, reporting perceived gains in language development and motivation (Kastler et al., 2019; Ramirez-Marin \& de Veritch Woodside, 2019) as well as personal transformations such as increased intercultural sensitivity and competency (Crawford \& Swartz, forthcoming) and worldview (Dietrich, Ekici, \& Minett, 2019). Along with other recent studies on student voices, these investigations provide insight into how participating in a COIL project impacts students' perspectives and motivation for learning in various settings. Despite the increased focus, however, this research area is still in its infancy, and more studies are needed to shed light on diverse student experiences. In any form of learning - including face-to-face, online, and blended environments - individuals have different reasons for wanting to learn a language and for cultivating their own unique experiences, something which is constantly affected by the context's internal and external forces.

The purpose of this paper is to illustrate how a student's language learning motivation was negotiated while participating in a mobility-based COIL project. Motivation in second language (L2) learning has been studied by many prominent researchers (Dörnyei, 2001, 2005, 2009; Gardner, 1985, 2001; Ushioda, 2003), and has gone through a major conceptual shift from that of the learner's static, psychological state of mind to a dialogic process whereby learners negotiate internal and external 
factors over time. Learners have different reasons for learning a language and different degrees of motivation, and various factors constantly interact with each other as the learner participates in a dialogic activity. This paper adopts the activity theory perspective (Lantolf \& Thorne, 2006; Vygotsky, 1978) on motivation, which presupposes the learner and their environment to be historically and culturally configured and undergoing constant transformation. Specifically, this paper closely looks at a learner's negotiation of his L2 motivation through the mobility-based COIL project.

\section{Literature review}

\subsection{The concept of motivation in language learning research}

In the early days of the L2 learning field, the most prevalent approach to studying motivation was Gardner's (1985) socio-educational model where L2 motivation was divided into effort, desire, and attitude toward learning. This model employed a reductionistic perspective on motivation through the quantitative, psychometric analysis of certain groups' L2 learning motivation as a whole, rather than on L2 learners' individual motivation (Kim, 2010). Moreover, his notion of integrativeness, defined as "genuine interest in learning the second language in order to come closer to the other language community” (Gardner, 2001, p. 5), was gradually losing its significance in the changing climate and globalized environment for L2 learning.

Coinciding with the field's paradigm shift in the 1990's - where increasing significance on sociocultural, interactive aspects of L2 learning gained more focus - L2 motivation models also became diversified and started to acknowledge the importance of cultural and contextual factors for motivation as well as individual perspectives. Dörnyei developed a more comprehensive model of motivation with the notion of an L2 motivational self-system consisting of Ideal L2 self and Oughtto L2 self (Dörnyei, 2001, 2005, 2009). The ideal L2 self is a learner's internalized prosperous selfimage that successful L2 learning leads to, while the ought-to self is a learner's sense of obligations stemming from their fear of unsuccessful L2 learning and its negative results in their life. This model captures the longitudinal dynamics of how L2 learning motivation is manifested by each student's self-system in relation to the learning environment.

L2 motivation research was further advanced by adopting Vygotskian sociocultural theory (Lantolf \& Thorne, 2006; Vygotsky, 1978) which emphasizes the role of social interactions in language learning and the cognitive functions of such dialogic activities. Learning is a culturally rooted, socially mediated process of constructing knowledge, and learners must be active agents in the process and have a desire to learn in order for learning to occur (Ryan \& Deci, 2002). As learning 
takes place through participation in socio-culturally mediated interactions, the motivation to learn is also socially and culturally mediated (Ushioda, 2003). This framework shows the dynamic sociocultural process between the learner and the context, within which the impetus to learn may or may not arise. The motivation can then develop, or fade away, as a result of interpersonal and intrapersonal negotiation over time. As Ushioda (2003) argues, motivation is not solely a static mental state of an individual, but rather it needs to be captured with a comprehensive holistic approach.

\subsection{Activity theory approach to motivation}

Drawing on sociocultural theory, activity theory was developed by scholars such as Leont'ev (1974) and Engeström (1987, 1999, 2001). Activity theory comprises an activity system conceptualizing three mutual relationships between subject, object, and community. Each relationship is mediated by instruments, rules, and division of labor, respectively (Figure 1).

Figure 1. The structure of a human activity system (Engeström, 1987)

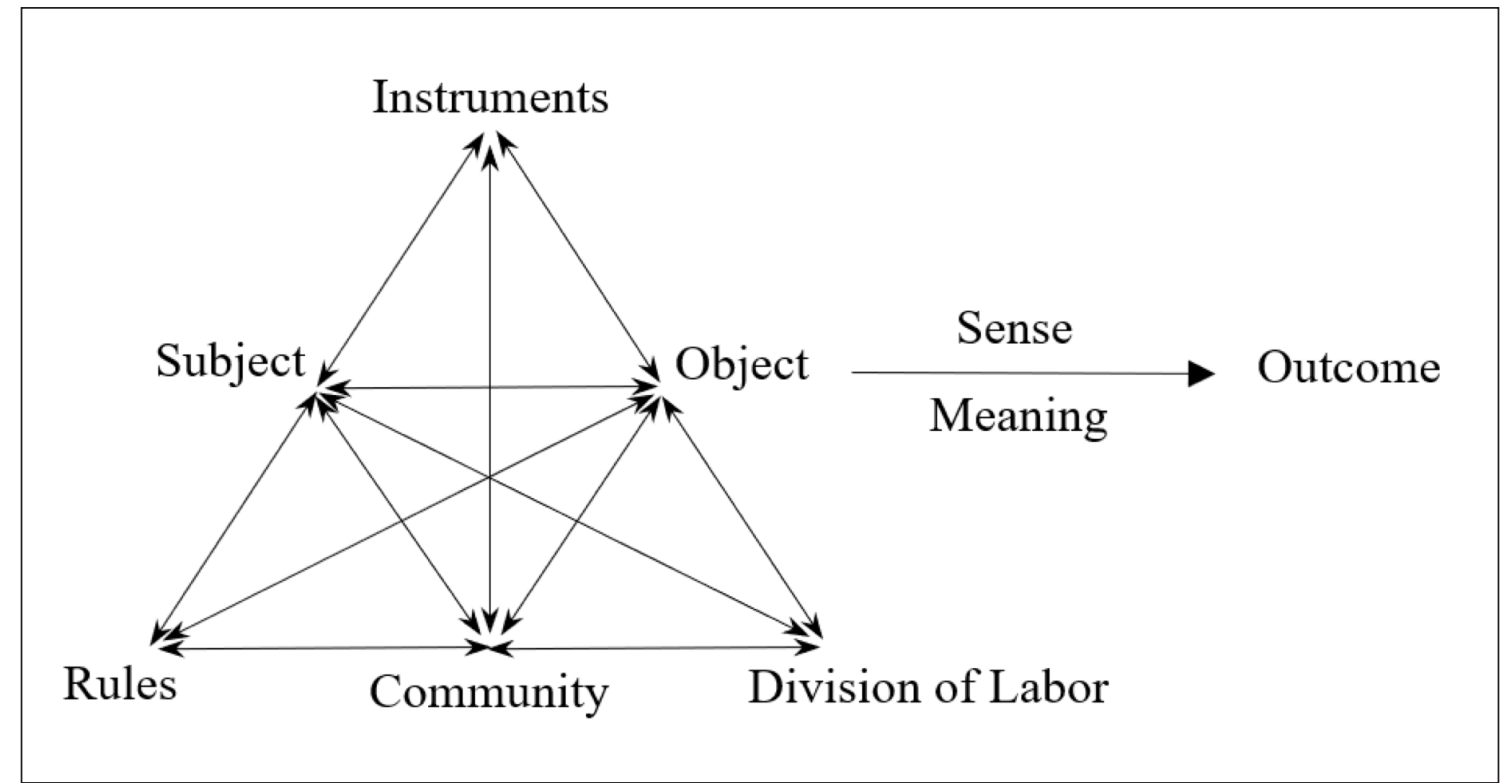

According to Engeström (1987), a subject is an actor whose viewpoint is employed in the analysis, and an object refers to a focal entity or desired outcome. A community denotes a group that shares with the subject an interest in and involvement with the object. The subject employs instruments, 
any materialistic or conceptual tools, to act on the object. Rules comprise regulations on the subject's action toward the object, and the division of labor refers to the explicit and implicit organization of the community, denoting who does what for the desired outcome. Not only is each component culturally and historically configured, it is interconnected with others, as all are continually affecting and being affected, one by the other.

As illustrated by this model, human activities are object oriented, collective, culturally mediated, and motivated by specific biological or culturally constructed needs (Engeström, 1987). A 'need' is the general orientation of a student's activeness (Markova, 1990) and it becomes a motive once it is directed at an object (Allen, 2010). As an object is the central focus of an activity system, the objectification of a need transforms it into a motive, thereby giving direction to the activity (Engeström, 1999). More specifically, a motive is the cultural-psychological-institutional impetus that is considered to be both inherently unstable and transformed as the activity is developed over time (Lantolf \& Thorne, 2006; Markova, 1990). In turn, an activity comprises a series of actions, and actions are oriented toward goals. While goals regulate an activity with a clear beginning and end, they are transformative, like motives (Engeström, 1999). An activity is thus instantiated concretely as a goaloriented action (Allen, 2010). A motivation is developed when a motive is integrated with specific goals and a sense of participation (Kim, 2010). In other words, a motivation is socially generated and mediated in the subject's unique experience of sense-making of the activity.

\section{Figure 2. The development of motivation from an activity theory perspective (Kim, 2010)}

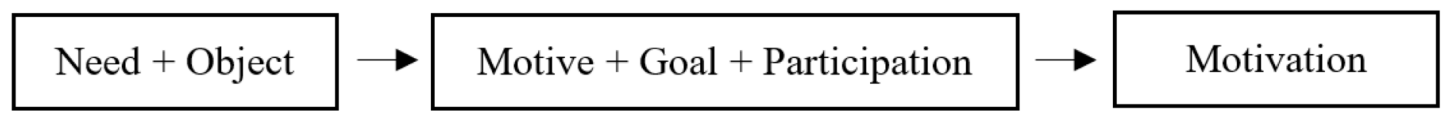

Kim (2010), through his analysis of motivation of Korean English as a second language learners in Canada, presented the visualized model of this motivational process based on activity theory (Figure 2). Adopting Kim's (2010) model, Allen (2010) investigated language learning motivation during a short-term study abroad program in France from an activity theory perspective. In her case study of six participants, she identified types of motives and analyzed how enhanced language learning motivation emerged to varying degrees. These studies illustrated how motivation is dynamically negotiated in the historically and culturally configured interactions between the learners and their environments.

In this study, activity theory served as a useful analytical lens for examining the motivational process of the student, Jason, by illustrating how his motivation was negotiated through his engagement 
- "the amount of physical and psychological energy that the student devotes to the academic experience" (Astin, 1993, p. 297) - in the COIL project with regard to the activity of language learning. The following questions guided this study:

- what motives informed the student's engagement in Japanese learning, and how did his COIL participation relate to these motives; and

- how did participation in COIL enhance the participant's language learning motivation?

\section{Methodology}

\subsection{Settings}

This study was situated in a COIL project between the University of North Georgia (UNG) and Nanzan University (NU) that took place in spring 2019. UNG is a public university with a relatively new Japanese program, and is located in a rural area of Georgia, in the United States. NU is a private, liberal arts university with well-established international programs and is located in the city of Nagoya, Japan. The two institutions started exchange and COIL partnerships in 2018 and offer various COIL programs and courses including ones involving student mobility. One such program is called Sakura Project, which was launched in early 2019. As designed, UNG and NU students collaborate online for six weeks, followed by the participation of NU students in a two-week study abroad program at UNG for face-to-face collaboration. The learning objectives of the project were (1) to enrich intercultural collaborative skills through working together in comparing college life in Japan and in the United States and (2) to improve students' practical abilities in the target language, especially reading and communicative skills.

A total of four UNG students who enrolled in the Japanese Cultural Research course participated in the project as part of the course requirements. The course was taught in Japanese and was designed to provide students with research opportunities in the language. The students had taken at least two years of Japanese at UNG or elsewhere, and they ranged between intermediate to low-advanced in terms of Japanese proficiency. On the other hand, at NU, this project was set up as a non-creditbearing, faculty-led, two-week study abroad program to UNG, with pre-departure COIL. Due to the mobility-based nature of the project, NU's COIL office conducted internal application screenings to select the best qualified participants. Application was open to all undergraduate students and ten NU students were selected from various majors, such as British and American studies, policy studies, economics, and Christian studies. English proficiency levels varied from low-intermediate to advanced. 
The theme of the collaboration was college life in Japan and in the United States. Prior to the collaboration, institution-specific and joint orientations were carried out in early January, and four groups were randomly created, each of which consisted of one UNG student and two to three NU students. The COIL activities included reading texts in the target language and in-group text discussions on the app called LINE, as well as video discussions on Skype, weekly journals, and individual essay writing in the target language. The online discussion phase consisted of two periods: (1) a three-week discussion on 'Japanese college life' in Japanese, and (2) a two-week discussion on 'American college life' in English. Toward the end of the second period, each group selected a subtopic for American college life that they would use in creating an informational video, in English, during the face-to-face period. After the project, each student was interviewed by the teacher-researchers (i.e. authors) at each institution. A learning management system called Canvas served as the platform for administrative purposes such as material distribution as well as assignment submission and assessment.

\subsection{The student: Jason}

While in-depth data analysis was conducted for all participants, we selected one student, Jason, following the purposive sampling approach whose key criteria are relevance to research questions, analytical framework, and analytical practice (Etikan, 2016). It was not the extreme nature of his experience in the transformation of motivation that makes his case stand out; rather, Jason was the most expressive of his transformation, which was instantiated in various ways. While multiple similar instances of transformation of motivation were observed in other participants, Jason's case seems to be best suited to the purpose and analytical lens of this study due to his willingness to participate in the project, his rich experience in it, and his ability to communicate his experiences and opinions in an articulate, expressive, and reflective manner (Etikan, 2016).

Jason was a 22-year-old graduating senior, as of the spring 2019 semester, majoring in English with a writing and publication concentration. He started learning Japanese at UNG in 2016 and was completing his minor in Japanese with the Japanese Cultural Research course, where the Sakura Project took place. His proficiency in Japanese was intermediate. He had never been to Japan or to any other countries outside the United States. He had three NU partners for this project and worked with them on the subtopic of 'extracurricular activities' in American college life during the face-toface period.

\subsection{Data collection and analysis}

In the early phase, the grounded theory approach with ethnographic methods guided this study, with the aim of interpreting participants' perspectives about motivation for language learning and/ 
or COIL. The original data comprised questionnaire answers, LINE chat logs, Skype recordings, journals, essays, interview recordings and transcriptions, and researchers' field notes for all NU/UNG participants. The questionnaire answers provided participants' demographic information, concerns and expectations for the project, and post-project evaluations and reflections. Participants submitted a journal entry weekly reflecting on their own performance in English. Each group was required to submit LINE chat logs and Skype recordings at the end of the project. Individual interviews were conducted at each institution after the project, primarily as a follow-up to the second questionnaire. Participants were asked in the primary language of the institution to provide in-depth reflections on the program as well as their language learning experience and motivation, based on open-ended questions prepared by the teacher-researchers.

Initially, our research question was broad: how does participating in a COIL project affect learners' language learning motivation? In addition to the text-based data, individual interviews of all participants were transcribed. The collected data was analyzed on NVivo, a qualitative data analysis software, drawing on the principle of constant comparison in order to identify a certain phenomenon and its local features, and to provide an ongoing reflection of the researcher's interpretation of the phenomenon (Glaser \& Strauss, 1967). In doing so, patterns and themes were identified using a grounded theory-based, inductive strategy (Strauss \& Corbin, 1998), which comprises a set of flexible guidelines for three types of data coding: open coding, axial coding, and selective coding. During the stage of open coding, data is broken down, examined, compared, conceptualized, and categorized (Strauss \& Corbin, 1990). The same data then undergoes the process of axial coding where data are put back together in new ways by making connections, followed by selective coding where the core category is selected, other categories are further refined and developed, and systematic relationships between categories are formed and validated (Strauss \& Corbin, 1990). Preliminary codes and interpretations of data were regularly triangulated within multiple data sources and cross-referenced between the teacher-researchers. After a repeated analysis of the data, Jason's case was found to be the most descriptive of language learning motivation and its transformations in terms of deep reflections on one's own language learning experience as well as on the perceived differences between the pre-COIL and post-COIL selves. Through this process our research questions were refined from the broad question into the more specific ones. As a result, Jason was asked to participate in three additional interviews that were then transcribed and cross-referenced and triangulated with the original data (Table 1).

Thus, this study took a methodological turn away from being a mere ethnography toward a blended, focused-ethnography and case study design, which allowed not only the exploration of student feelings and beliefs (Fusch, Fusch, \& Ness, 2017), but also the identification of operational links between events over time (Yin, 2014). Going beyond traditional ethnography in education 
where researchers "enter a classroom, school, family group or community setting to identify insider knowledge by asking questions" (Green, Skukauskaite, \& Baker, 2012, p. 310), this study was particularly informed by the concept of virtual ethnography, which uncovers, describes, and understands what is constituted in relationships at the local level, facilitated through virtual dimensions (Antoniadou \& Dooly, 2017). Virtual ethnography views multi-source data, both online and offline, as a socially meaningful communicative practice that informs one to another. Following this scope, Jason's data was examined in order to understand interrelated patterns between virtual and physical sites.

\section{Table 1. Jason's interview breakdowns}

\begin{tabular}{|l|l|l|l|}
\hline Interview\# & Length & Topics & Notes \\
\hline 1 & 20 minutes & $\begin{array}{l}\text { ・ Overall reflection of the project } \\
\text { - Language learning experience } \\
\text { - Perceived changes }\end{array}$ & $\begin{array}{l}\text { As a part of the project } \\
\text { requirements }\end{array}$ \\
\hline 2 & 60 minutes & $\begin{array}{l}\text { - Personal history of language/culture learning } \\
\text { - Struggles in language learning } \\
\text { - Perceived changes } \\
\text { - Podcast project for multimodal course } \\
\text { - Future plans }\end{array}$ & Additional interviews \\
\hline 4 & 40 minutes & \\
\hline
\end{tabular}

\section{Findings}

\subsection{Pre-COIL motives}

Jason started taking Japanese courses at UNG when he was a sophomore. As an English major, he needed a minor by taking language courses for four semesters. Jason decided to take Japanese because he had "always been interested in Japanese because my great-grandmother was Japanese" (Interview \#2). Other than occasional visits to his great-grandmother, Jason did not have an extensive exposure to the Japanese language or culture. However, he recalled his choice "must have come from my heritage and cultural connection to my great-grandmother” (Interview \#2).

As a self-proclaimed introvert, Jason did not necessarily like foreign language learning as a teenager because it required him to speak in front of other students, using a language in which he lacked 
proficiency. Understandably, his learning Japanese in college carried a similar burden, as he recalled that "the first two semesters were kind of difficult for the same reason" (Interview \#2). However, his classroom experience became much easier as a result of growing more comfortable in the learning environment, including in his interactions with teachers and classmates, and engaging in public speaking in his other courses.

Jason had not intended to continue with learning Japanese after college as he initially "just wanted to get a minor and maybe kind of learn Japanese okay" (Interview \#1). He did not have specific expectations for cultural learning either, nothing more than what he thought he "would at least pick up a little bit about Japanese culture” (Interview \#1) in the Japanese courses. He did not watch anime, read manga, or play Japanese video games like many students in Japanese courses did, and his "only exposure to Japanese culture before taking the class was on [his] great-grandmother” (Interview \#2).

In the course of learning Japanese at UNG, Jason's interest and desire to become proficient in the language and to know more about the culture increased and were manifested in various ways. He started participating in cultural events and subscribing to online Japanese news. In addition, it came as a pleasant surprise for Jason that the linguistic courses he took as part of his major requirement gave him a different standpoint to view Japanese as a target of linguistic analysis. He came to "understand Japanese more deeply through the objective lens, which helped me learn it better" (Interview \#3).

Jason was going to participate in a nine-week study abroad program in Japan through UNG to improve his Japanese skills and to obtain greater cultural exposure to Japanese lifestyles. Unfortunately, this opportunity coincided with "a dream internship opportunity in publication", and he therefore could not participate in the program (Interview \#4). Around the same time, he also started thinking about living in Japan in the future and applying to a program to teach English in Japan upon graduation.

Jason's language learning experiences, both in middle school and college, stimulated his general interest in technology; this led him to write a term paper about language learning and technology that he eventually presented at a UNG student conference. In his paper, Jason argued that technology could be used to help children learn languages better, despite the prevailing negative attitude toward technology use in classrooms or doubts of its usefulness in learning. When he wrote this paper, he was taking his fifth, in-person Japanese course at UNG where each student used a tablet and a stylus for all course activities. Also, there was a telecollaboration project with a university in Japan where UNG students interacted online with their Japanese peers. The course was "the most digitized faceto-face course" Jason had taken which he "struggled at first in getting used to the technological tools but really enjoyed and found them to be very useful in learning” (Interview \#3). 
Jason's motives to learn the Japanese language and culture were multi-faceted and transformative. He started mainly with a culturally oriented motive that stemmed from his heritage, as well as a pragmatically oriented motive of completing a minor. He then developed a stronger interest in the Japanese language and culture through his learning experiences both inside and outside of the classroom. His growing interest in Japanese language and culture led him to seriously consider participating in a study abroad program and to live in Japan in the future. Moreover, the linguistics courses he took for his major further stimulated his intellectual curiosity in the language and helped him understand the language more logically. Thus, his experience of Japanese learning, combined with his interest in the technology use for language learning, developed the intellectually oriented motive. These motives did not necessarily develop in a chronological order, nor did they have clear starting points and ends. Some came earlier, while others came later. Some were stronger than the others at one point, while the others developed further or faded away. A unique mixture of various motives coexisted in Jason's activity of learning Japanese, and it was always negotiated by multiple factors.

\subsection{Goals and COIL participation}

Jason set various goals for the Sakura Project, including those of a pragmatic, cultural, linguistic, and intellectual nature. His pragmatic goal was the clearest from the beginning: to successfully complete the Japanese Cultural Research course for his minor requirement. He needed to complete the course to graduate at the end of the semester he took it in. He was informed of what the course would entail during the registration period. Having liked the telecollaborative project in the other Japanese course he took earlier, he decided to take this course in hopes that, as a result, he could interact to a greater degree with Japanese college students. To allocate as much time to the course as possible, he decided to take three online courses that semester because they were "less time-consuming" (Interview \#1).

Jason's cultural goals mainly comprised getting a good understanding of cultural topics and learning Japanese communication styles. The first half of the project involved the cultural topic of "Japanese college life", for which UNG students read Japanese texts and engaged in in-class discussions to prepare for online communication with NU students. He formulated discussion questions based on the readings and his preexisting knowledge about college life in Japan. As he recalled,

"it was very interesting to ask about what I read and see if that applies to my partners... Sometimes it was like the reading said or what I heard or read somewhere else, but other times they surprised me with something I had no idea about” (Interview \#2).

Linguistically, Jason aimed to improve his conversation skills and to reduce grammatical errors in his speech. He described his struggle in Interview \#3: 
"Before the project it felt like I hit a wall as far as learning... For a while I kind of felt that no matter how much grammar or words I learned, I wouldn’t be able to speak Japanese”.

Jason took this project as an opportunity to break that wall. When the project was in the Japanese period, he tried to stick to Japanese when talking to NU students. When NU students arrived at UNG and the group started to create a video in English, he tried to use as much Japanese with his partners as possible. When his group visited the Pistol Club to record a video clip, they were invited to experience gun shooting by the club's president. Jason translated the shooting instructions into Japanese for his NU partners' understanding and, ultimately, safety.

Not only did the face-to-face period facilitate Jason's speaking in Japanese, the entire project period afforded him the opportunity to speak Japanese more than ever. While Jason met with a Japanesespeaking tutor at UNG on a weekly basis, their meeting was for 30 minutes and was somewhat structured, given the assigned materials on which they were supposed to work. While this project was structured in a similar sense, it also gave him ample opportunities to engage in more social and personal interactions along the way (Interview \#3):

"I definitely spoke more Japanese in those weeks than I did for the whole previous semester. It was really the first time that I've had an opportunity to have extended conversations in Japanese and I thought I would struggle a lot more. It showed me I could actually use what I had learned up until that point more in a real-world situation”.

Having three NU partners, Jason described himself as "a kind of US ambassador who answers all the questions they had" (Interview \#2), putting him in the position to talk more than any other member of the group. Due to the setup of this project in which NU students visited UNG, Jason was the host showing them around, introducing them to his friends, and explaining various things as his NU partners expressed their interest. The extensive experience of speaking Japanese gave him confidence in Japanese conversation, something he thought he was falling behind in before the project began.

Jason also had an intellectual goal of evaluating the effectiveness of the technology-enhanced project for his own language learning as well as for those in general. A few weeks into the Sakura Project, Jason wrote an email to the UNG teacher-researcher:

"For my multi-modal writing class this semester, I am required to do a podcast [where] I would like to discuss how using technology can be beneficial for learning foreign languages. I think you could tell me a lot about the process of setting up our project as well as explain 
from a linguistic perspective how it is beneficial to have communication with Japanese speakers”.

Following up on the paper he wrote for the student conference in the previous semester, Jason decided to continue his research in the field of language learning and technology, drawing on the Sakura Project. During the interview with the teacher-researcher for his podcast, he asked: (1) is there any linguistic theory behind the usefulness of technology when learning a language, (2) what was the process for teachers getting the Sakura Project set up, and (3) are there any other ways to communicate with speakers of one's target language using technology? Additionally, other questions branched out from these three main topics. During the post-project Interview \#4, he commented why he wanted to do the podcast:

"I wanted to talk about how technology can be used to help learning a language like it helped me. I don't think I would be as good at Japanese as I was at the time if it weren't for doing the Skype calls or having face-to-face interactions in the project”.

After discussing the linguistic effectiveness of interactions - such as meaningful input and output, as well as differences in nature between online and face-to-face interactions - Jason also appreciated the project as an opportunity to enhance his overall understanding of Japanese through the real-life application of his knowledge and skills (Interview \#4):

"The reason why I was interested in the project was it was more about a bigger picture, or real-world application, obviously. It helps me organize things or get a better understanding of Japanese on a broader scale”.

While Jason's intellectual goal of evaluating the effectiveness of technology use in language learning was peripheral to the Sakura Project, in that the podcast was for a different course he was taking, it all started from and directed back to his own experience of Japanese learning using technology. Through the process of podcast making, Jason was able to objectively evaluate how his experience in the Sakura Project helps his overall objective of learning Japanese.

\subsection{Negotiation of language learning motivation}

Jason's pragmatic goal of successfully completing the course and graduating with a minor in Japanese was not dominant compared to his other goals, as he was always a diligent student. What was more important to him was improving his Japanese proficiency (Interview \#3): 
"I hit this wall in my third or fourth semester where I understood how to study Japanese, how to memorize vocabulary and kanji, and study grammar, but I couldn't really speak it or listen. I think this project helped me get past that barrier a little bit. Now I can catch what someone says to me in Japanese and I can respond in Japanese”.

Through participating in the Sakura Project, Jason reevaluated his own skills in a positive light. However, it also showed him those areas still in need of improvement, as he could not hold a conversation fully in Japanese when the situation required more complex vocabulary or communicative skills. In addition, he mentioned it "was kind of demotivating" to realize how much of what he had learned before was now forgotten. Mixed with his emerging confidence, Jason sensed the need to improve his skills, which enhanced his long-term objective of learning Japanese (Interview \#3):

“I don't want to graduate and then just stop that in Japanese because it’s going to be a big waste. After I graduate, I'll go back through all the books that we've been through and review everything”.

While Jason's motivation to "really learn Japanese", instead of "learning it okay" had already emerged earlier in the course of his Japanese learning experiences, it had been hindered by the continuous doubt as to whether he would ever achieve functional proficiency in Japanese. However, participating in the Sakura Project, which gave him confidence and showed him what to work on, further enhanced his motivation to become more proficient in Japanese.

Jason's participation in the Sakura Project also enhanced his goal of going to Japan to teach English upon his graduation. While the desire to apply for the program slowly grew as he progressed through college life, he was determined to fulfill this aspiration by the time of the Sakura Project. However, the time frame was uncertain, as he was planning to work for a few years in the United States first, in the field of publication or editing. In his third follow-up interview, which took place a month before his graduation, however, he had "given a serious thought about it and decided to apply this year". As he admitted, "there are many personal reasons" but the Sakura Project was "one of many factors that contributed to the decision".

Jason's intellectual motive to evaluate the use of technology in language learning led him to enrich his knowledge about various technological tools. In consequence, Jason was encouraged to use these tools outside classrooms. While he commented that "face-to-face interaction is the best because it's the most organic form of communication", he appreciated the effectiveness of both 
written communication and video calls for different reasons (Interview \#3). In his podcast, Jason presented various online services where one can communicate via video calls as he thought "video calls are really helpful for those who don't have the opportunity for face-to-face communication" (Interview \#1). He also introduced several text-based online services because he found texting to be helpful "as it gives us time to think - formulate what we really want to say properly" (Interview $\# 1)$.

Jason's language learning motivation was enhanced by his participation in the project and in achieving particular goals. The most noticeable - and unexpected - of these was the greater degree of linguistic goals he refined via gaining confidence and realizing what needed further improvement. He “wouldn't have realized how much [he] could actually use [his] language skills if it weren’t for the project” (Interview \#3). Comparing his experience in the Sakura Project to studying abroad, which he could not participate in through college, Jason appreciated the "exposure to conversation like that” as something one cannot easily access unless they are not studying abroad (Interview \#3):

"The project was really fun and helpful... It was like I was studying abroad in Japan but without actually going there. Instead, they came to me”.

\subsection{Process of motivation and demotivation}

Jason went through the process of demotivation (Dörnyei, 2001; Kim, 2010; Kim \& Kim, 2013) prior to the COIL project (Figure 3). Demotivation captures the process of gradual disintegration of a motive, goal(s), and participation (Kim, 2010). In Jason's case, his linguistic motive emerged through gaining more knowledge of the Japanese language in class. The motive was integrated with participating in class activities, homework, or individual learning of the language outside the classroom, resulting in the motivation to speak Japanese fluently. However, the object was not well served due to the misfit with the community and the instruments. The community comprised his classmates, who were taking the courses for various reasons and with different expectations. While the language of instruction was mainly Japanese in his courses, his peers did not always speak Japanese in class unless they were instructed to do so. In addition, in-class practice with peers was the only opportunity for him to speak Japanese, which he felt was not enough to achieve a level of fluency in the language. Moreover, the instruments were not particularly geared toward improving oral proficiency, which created a misfit with the object from where Jason stood. These misfits within Jason's activity system gradually decreased confidence in his oral skills over time, which by the time he participated in the Sakura Project, led him to believe that he would never be able to speak the language fluently. 


\section{Figure 3. The structure of Jason's activity system before the COIL project}

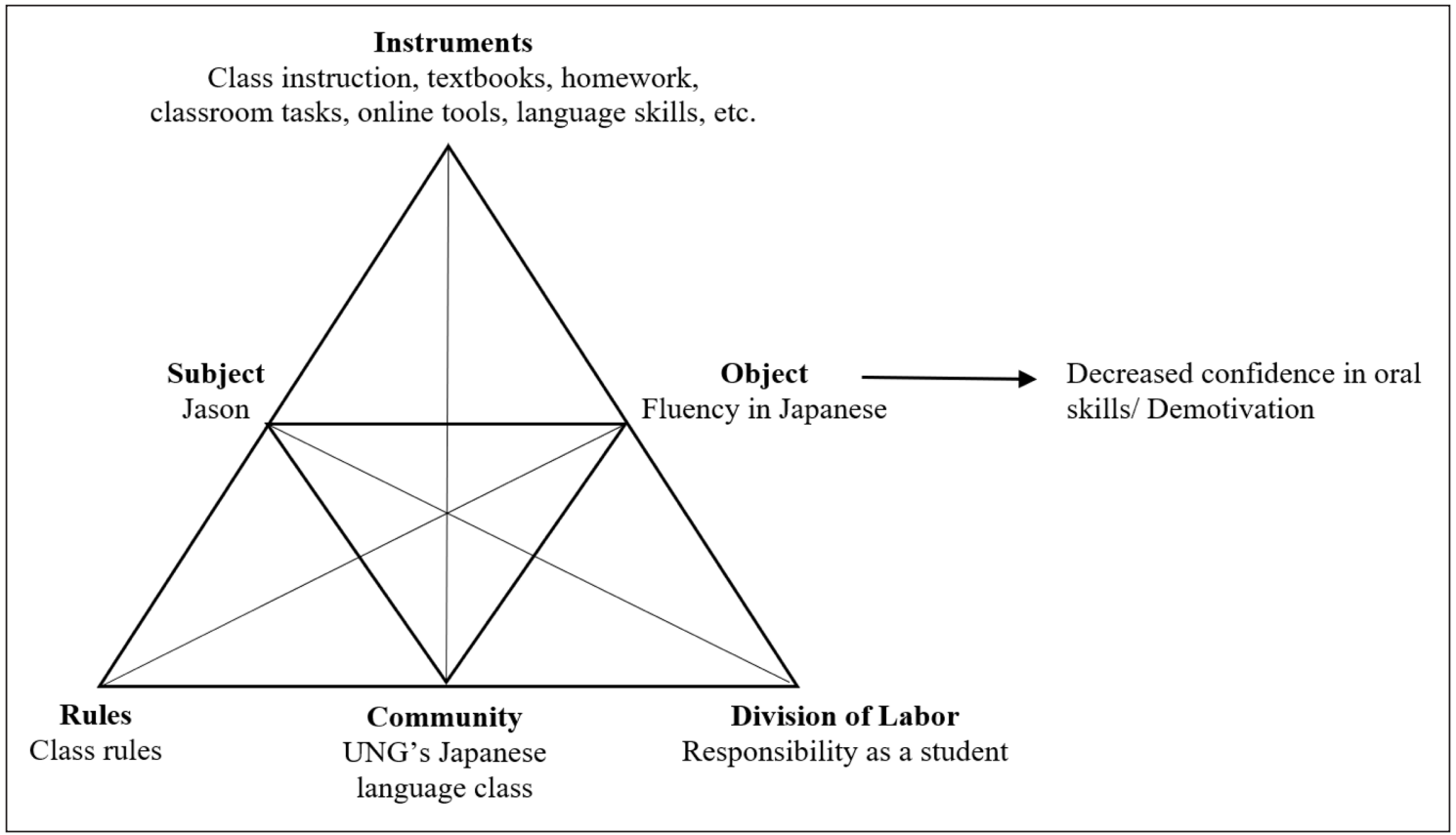

The COIL project brought new dynamics to Jason's activity in a positive manner (Figure 4), reenacting the process of motivation. The community consisted of his COIL group and the UNG course where Japanese-speaking learners of English outnumbered English-speaking learners of Japanese. The rules regulated their language use; all students were to use Japanese only during the first discussion period, which encouraged Jason to speak Japanese more. LINE and Skype, the instruments, provided Jason with ample opportunities to practice communicative skills, in contrast to his past classroom experience. The division of labor also worked in Jason's favor because he was the only UNG student in his group; he did not have to take turns to speak Japanese among UNG peers, and he was able to contribute to group discussions to the fullest. In addition, he showed NU students around campus when they were at UNG, which put him in the dual role of Japanese-speaking guide and buddy to support their short-term stay in the United States. Thus, the Sakura Project reconfigured the components of Jason's activity system and removed the existing misfits between the object and the instruments and community that had resulted in demotivation. In his case, increased opportunities and the sense of need to speak Japanese contributed to his image of an ideal learning environment, which over time reversed the demotivation to motivation. 
Figure 4. The structure of Jason's activity system during the COIL project

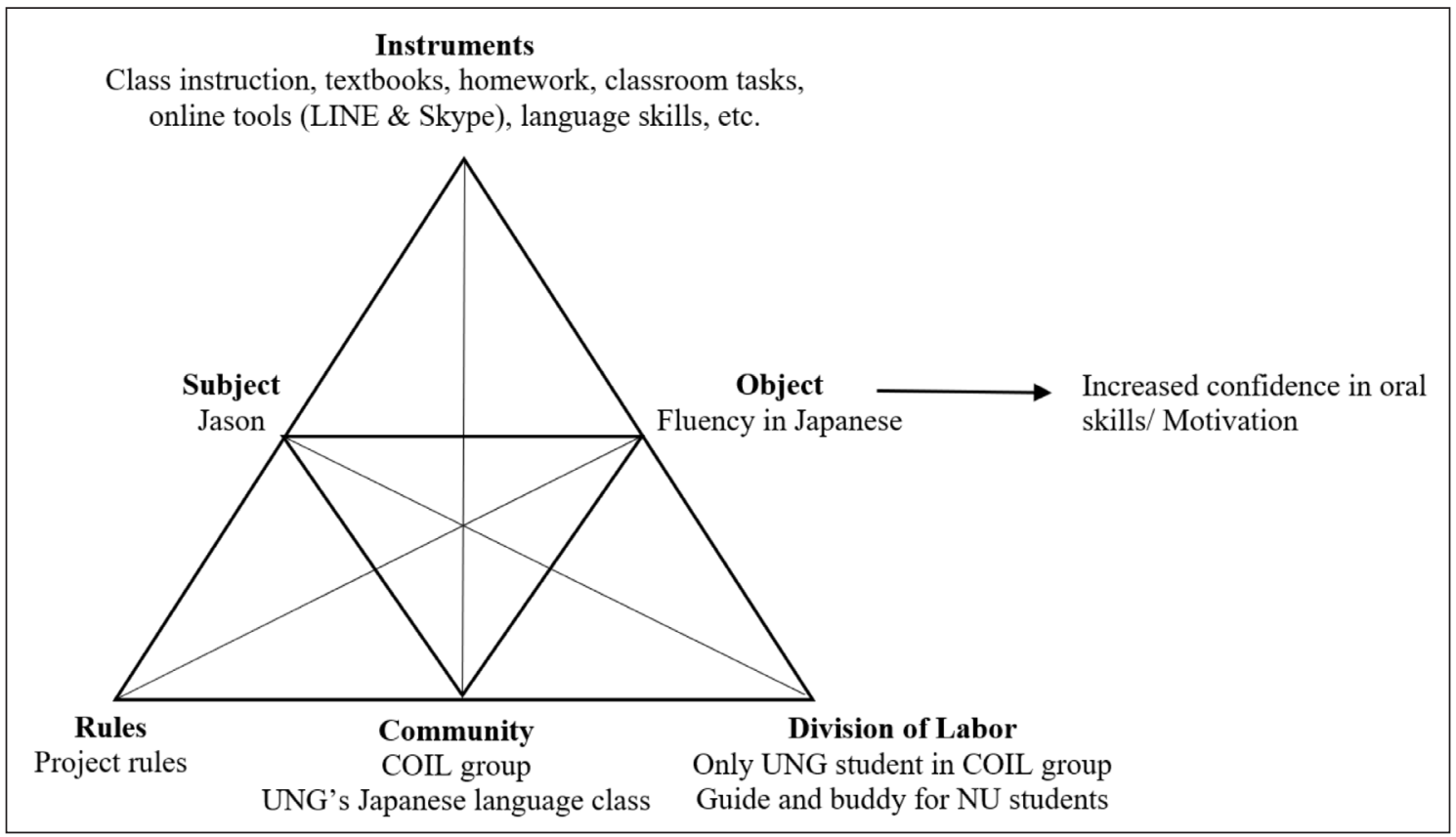

Jason's other motives - such as the pragmatic, cultural, and intellectual ones - were also negotiated via his participation in previous Japanese courses and other extracurricular activities, resulting in forming motivations with personal significance. For example, his intellectual motive to learn Japanese with technology derived specifically from his personal experience, which was instantiated in specific goals to use technology for his own learning as well as to write a paper on the topic for intellectual purposes. These goals were developed through integrating the motive and participating in language learning, resulting in an intellectual motivation loaded with personal significance. Participating in the COIL project further enhanced the motivation instantiated in podcast making, adding more importance to the use of technology in his learning.

\section{Discussion and conclusion}

Revisiting the research questions, Jason's engagement in Japanese learning was informed by cultural, linguistic, pragmatic, and intellectual motives through their dynamic interplay over the years. His participation in the COIL project reenacted the process of motivation through social, dialogic actions 
in his activity triangle and enhanced his overall motivation to learn Japanese. Originally motivated by the cultural connection to his great-grandmother and the pragmatic need to earn a minor in a language, he developed his linguistic motive over the years as he progressed in the Japanese courses. The cultural motive also expanded from the heritage-based impetus to growing interest in various aspects of Japanese culture. Moreover, he developed an intellectual motive of incorporating technology to his language learning, which emerged as his actions of presenting a paper at a student conference and starting a podcast for his other course on the topic.

As Kim (2005) points out, motivation results from the interplay between an individual and their environment; thus, Jason's process of motivation was unique for his own personal history and social relationships. His motives were always dynamically negotiated, and they were transformed into a language learning motivation that was personally significant (Negueruela-Azarola, 2011; Yang \& Kim, 2011). As Kim and Kim (2013) emphasize, internal and external factors come into play in the process of motivation and demotivation. Jason's demotivation resulted from a complex social process, as certain gaps emerged in his activity triangle, instantiated as a perceived struggle to achieve the proficiency for which he aimed. Despite the demotivation of learning that Jason was going through, he decided to participate in the COIL project encouraged by his preexisting motives and the hope that the project would give him the opportunity to achieve the proficiency he so desired. Intersected with the setup of the project, his overall motivation to improve his Japanese proficiency was enhanced as he gained confidence in his communicative skills. It was through his engaged participation that his motives and goals were negotiated and transformed into an enhanced motivation to learn Japanese, setting specific future goals and engaging in actions.

This study corroborates previous studies on motivation with activity theory perspectives (Allen, 2010; Kim, 2005, 2010; Kim \& Kim, 2013; Lantolf \& Genung, 2002), and illustrates the importance of conducting a multidimensional analysis of motivation in order to capture the dynamism of the situation as well as the transformations. Motivation is dynamically negotiated in the unique environment in which each learner is situated, and participation is crucial in this process (Kim, 2005, 2010; Kim \& Kim, 2013; Ushioda, 2003). Some motives were more strongly integrated with goals and participation in the COIL project, while others lay more in the background. Jason may have undergone a totally different process in the absence of this project, or if it had occurred at a different time. Motivation is neither an individual phenomenon nor a static state of mind (Ushioda, 2003); rather, analyzing it requires a close look at the historical and cultural configuration of the environment in which a learner is embedded.

From a pedagogical perspective, this study suggests that COIL affordances go beyond institutional objectives to internationalize a curriculum - they can also provide students with an opportunity 
for personally meaningful transformation in their level of motivation. While this study is not generalizable due to its focus on one student's experience, it implies that COIL projects bring new dynamics to students' language learning experiences as a whole, especially when they involve student mobility. Indeed, COIL practitioners should keep in mind how new approaches or methods employed in an interactive collaboration such as the Sakura Project can influence student behavior within a given regulatory framework, as well as how they stimulate student perspectives on the entire activity of learning a target language and culture in many ways.

\section{References}

Allen, H. W. (2010). Language-learning motivation during short-term study abroad: an activity theory perspective. Foreign Language Annals, 43(1), 27-49. https://doi.org/10.1111/j.1944-9720.2010.01058.x

Altbach, P., \& Knight, J. (2007). The internationalization of higher education: motivations and realities. Journal of Studies in International Education, 11(3/4), 290-305. https://doi.org/10.1177\%2F1028315307303542

Antoniadou, V., \& Dooly, M. (2017). Educational ethnography in blended learning environments. In E. Moore \& M. Dooly (Eds), Qualitative approaches to research on plurilingual education (pp. 237-263). Research-publishing.net. https:// doi.org/10.14705/rpnet.2017.emmd2016.630

Astin, A. (1993). What matters in college? Four critical years revisited. Jossey-Bass.

Crawford, I., \& Swartz, S. (forthcoming). What has this done for me? University student reflections on intercultural experiential learning. Journal of Virtual Exchange, 4(2021).

Dietrich, S., Ekici, D., \& Minett, A. (2019, September). Person to person peacebuilding and intercultural communication: perspectives from a virtual exchange [Paper presentation]. International Virtual Exchange Conference, Tacoma, Washington, USA.

Dörnyei, Z. (2001). New themes and approaches in second language motivation research. Annual Review of Applied Linguistics, 21, 43-59. https://doi.org/10.1017/S0267190501000034

Dörnyei, Z. (2005). The psychology of the language learner. Lawrence Erlbaum.

Dörnyei, Z. (2009). The L2 motivational self-system. In Z. Dörnyei \& E. Ushioda (Eds), Motivation, language identity and the L2 self (pp. 9-42). Multilingual Matters.

Engeström, Y. (1987). Learning by expanding: an activity theoretical approach to developmental research. OrientaKonsultit.

Engeström, Y. (1999). Activity theory and individual and social transformation. In Y. Engeström, R. Miettinen \& R.-M. Punamáki (Eds), Perspectives on activity theory (pp. 19-38). Cambridge University Press.

Engeström, Y. (2001). Expansive learning at work: toward an activity theoretical reconceptualization. Journal of Education and Work, 14(1), 133-156. https://doi.org/10.1080/13639080020028747

Etikan, I. (2016). Comparison of convenience sampling and purposive sampling. American Journal of Theoretical and Applied Statistics, 5(1), 1-4. https://doi.org/10.11648/j.ajtas.20160501.11 
Foster, M. (2015). Exploring internationalisation of the curriculum to enhance the student experience. Journal of Perspectives in Applied Academic Practice, 3 (3), 1-2. https://doi.org/10.14297/jpaap.v3i3.206

Fusch, P. I., Fusch, G. E., \& Ness, L. R. (2017). How to conduct a mini-ethnographic case study: a guide for novice researchers. The Qualitative Report, 22(3), 923-941. https://nsuworks.nova.edu/tqr/vol22/iss3/16

Gardner, R. C. (1985). Social psychology and second language learning: the role of attitudes and motivation. Edward Arnold.

Gardner, R. C. (2001). Integrative motivation and second language acquisition. In Z. Dörnyei \& R. Schmidt (Eds), Motivation and second language acquisition (Technical Report \#23, pp. 1-19). University of Hawai'i, Second Language Teaching and Curriculum Center.

Glaser, B., \& Strauss, A. (1967). The discovery of grounded theory. Aldine.

Green, J. L., Skukauskaite, A., \& Baker, W. D. (2012). Ethnography as epistemology. In J. Arthur, M. Waring, R. Coe \& L.V. Hedges (Eds), Research methods and methodologies in education (pp. 309-321). Sage.

Kastler, K., Meier, A., Berri, D., Bali, H., \& Kurzenhauser, N. (2019, September). Student perspectives on effective virtual exchange [Paper presentation]. International Virtual Exchange Conference, Tacoma, Washington, USA.

Kim, T. (2005). Reconceptualizing L2 motivation theory: Vygotskian activity theory approach. English Teaching 60(4), 299-322. https://doi.org/10.15858/engtea.68.4.201312.141

Kim, T. (2010). Reductionism, activity theory, and L2 motivation research: toward new concepts and definitions. The SNU Journal of Education Research, 19, 87-118. http://s-space.snu.ac.kr/bitstream/10371/73001/1/vol19_4.pdf

Kim, T., \& Kim, Y. (2013). Reconceptualizing L2 learning demotivation from a Vygotskian activity theory perspective. English Teaching, 68(4), 141-163. https://doi.org/10.15858/ENGTEA.68.4.201312.141

Kinginger, C. (2009). Language learning and study abroad: a critical reading of research. Palgrave Macmillan.

Lantolf, J. P., \& Genung, P. B. (2002). "I'd rather switch than fight”: an activity-theoretic study of power, success, and failure in a foreign language classroom. In C. Kramsch (Ed.), Language acquisition and language socialization: ecological perspectives (pp. 175-196). Continuum.

Lantolf, J. P., \& Thorne, S. L. (2006). Sociocultural theory and the genesis of second language development. Oxford University Press.

Leont'ev, A. N. (1974). The problem of activity in psychology. Soviet Psychology, 14(2), 4-33.

Markova, A. K. (1990). Ways of investigating motivation for learning in school children. Soviet Psychology, 28(6), 21-42. https://doi.org/10.2753/RP01061-0405280621

Negueruela-Azarola, E. (2011). Changing reasons as reasoning changes: a narrative interview on second language classroom motivation, telecollaboration, and the learning of foreign languages. Language Awareness, 20(3), 183201. https://doi.org/10.1080/09658416.2011.570348

O'Dowd, R. (2016). Emerging trends and new directions in telecollaborative learning. CALICO Journal, 33(3), 291-310. https://doi.org/10.1558/cj.v33i3.30747

O’Dowd, R. (2018). From telecollaboration to virtual exchange: state-of-the-art and the role of UNICollaboration in moving forward. Journal of Virtual Exchange, 1, 1-23. https://doi.org/10.14705/rpnet.2018.jve.1 
Ramirez-Marin, F., \& de Veritch Woodside, V. (2019, September). Cross-cultural learning through student voices in two Mexico-U.S. collaborations [Paper presentation]. International Virtual Exchange Conference, Tacoma, Washington, USA.

Rubin, J. (2016). The collaborative online international learning network. In R. O’Dowd \& T. Lewis (Eds), Online intercultural exchange: policy, pedagogy, practice (pp. 263-272). Routledge.

Ryan, R. M., \& Deci, E. L. (2002). Overview of self-determination theory: an organismic-dialectical perspective. In E. L. Deci \& R. M. Ryan (Eds), Handbook of self-determination research (pp. 3-33). University of Rochester Press.

Strauss, A., \& Corbin, J. M. (1990). Basics of qualitative research: grounded theory procedures and techniques. Sage Publications.

Strauss, A., \& Corbin, J. (1998). Basics of qualitative research: techniques and procedures for developing grounded theory. Sage Publications.

Ushioda, E. (2003). Motivation as a socially mediated process. In D. Little, J. Ridley \& E. Ushioda (Eds), Learner autonomy in the foreign language classroom: learner, teacher, curriculum and assessment (pp. 90-103). Authentik.

Villar-Onrubia, D., \& Rajpal, B. (2015). Online international learning: internationalising the curriculum through virtual mobility at Coventry University. Perspectives: Policy and Practice in Higher Education, 20(2-3): 75-82. https://doi.or g/10.1080/13603108.2015.1067652

Vygotsky, L. S. (1978). Mind in society. Harvard University Press.

Yang, J., \& Kim, T. (2011). Sociocultural analysis of second language learner beliefs: a qualitative case study of two study-abroad ESL learners. System, 39, 325-344. https://doi.org/10.1016/j.system.2011.07.005

Yin, R. K. (2014). Case study research: design and methods (5th ed.). Sage. 


\section{Virtual Exchange?}

Published by University of Groningen Press | UGP, a not-for-profit press

Groningen, The Netherlands | UGP@rug.nl

(C) 2020 UNICollaboration (collective work)

(C) 2020 by Authors (individual work)

Journal of Virtual Exchange 2020

Edited by Carolin Fuchs and Müge Satar

Special issue edited by Penelope Margaret Orton, Natesha L Smith-Isabell, and Mary Jane Radford Arrow

Publication date: 2020/11/27

Journal of Virtual Exchange (JVE) is an online, open-access, peer-reviewed journal aimed at practitioners and researchers in the field known variously as virtual exchange, telecollaboration, or online intercultural exchange. It is the official journal of UNICollaboration (https://www.UNICollaboration.org/), the international academic organisation dedicated to supporting and promoting telecollaboration and virtual exchange in higher-level education.

Rights. The whole volume is published under the Attribution-NonCommercial-NoDerivatives 4.0 International licence (CC BY-NCND 4.0); individual articles may have a different licence. Under the CC BY-NC-ND licence, the volume is freely available online for anybody to read, download, copy, and redistribute provided that the author(s), editorial team, and publisher are properly cited. Commercial use and derivative works are, however, not permitted.

Disclaimer. University of Groningen Press does not take any responsibility for the content of the pages written by the authors of this article. The authors have recognised that the work described was not published before, or that it was not under consideration for publication elsewhere. While the information in this article is believed to be true and accurate on the date of its going to press, neither UniCollaboration nor University of Groningen Press can accept any legal responsibility for any errors or omissions. Additionally, the publisher makes no warranty, expressed or implied, with respect to the material contained herein. While University of Groningen Press is committed to publishing works of integrity, the words are the authors' alone.

Trademark notice. Product or corporate names may be trademarks or registered trademarks, and are used only for identification and explanation without intent to infringe.

Copyrighted material. Every effort has been made by the editorial team to trace copyright holders and to obtain their permission for the use of copyrighted material in this article. In the event of errors or omissions, please notify the publisher of any corrections that will need to by incorporated in future editions of this article.

Typeset by Research-publishing.net (https://research-publishing.net)

Noto fonts are open source. All Noto fonts are published under the SIL Open Font License, Version 1.1. Noto is a trademark of Google Inc. (https://www.google.com/get/noto/).

ISSN: 2647-4832 (online only)

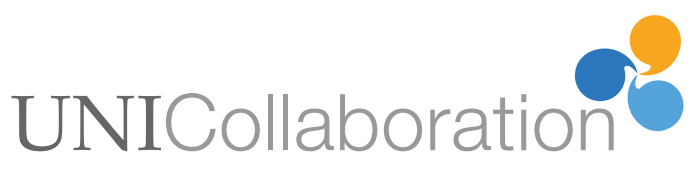

